
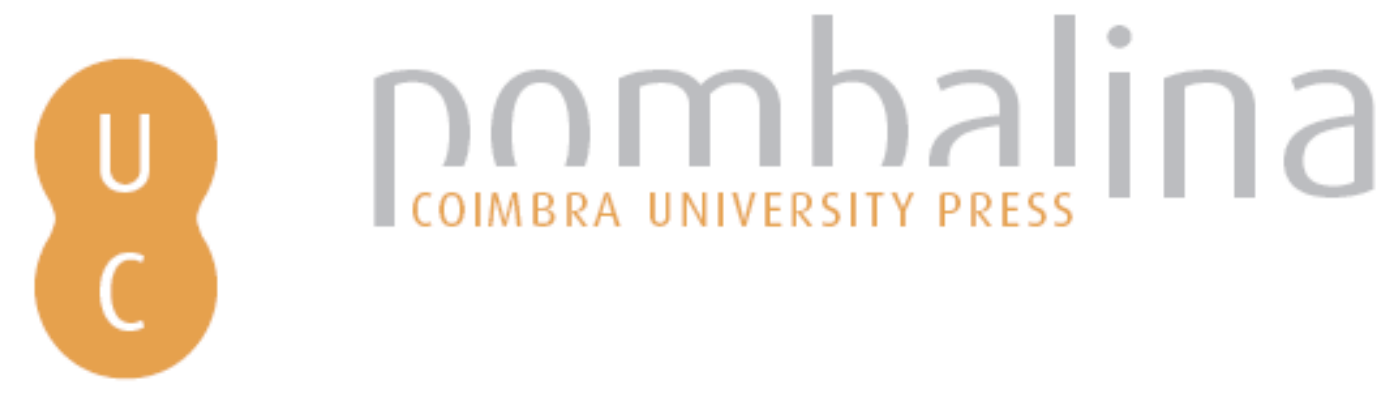

\title{
Para outras leituras da História da educação: o papel da arquitectura escolar
}

Autor(es): $\quad$ Rodrigues, António Simões

Publicado por: Imprensa da Universidade de Coimbra

URL

persistente:

URI:http://hdl.handle.net/10316.2/31632

DOI:

DOI:http://dx.doi.org/10.14195/978-989-26-0199-1_26

Accessed : $\quad$ 26-Apr-2023 13:40:25

A navegação consulta e descarregamento dos títulos inseridos nas Bibliotecas Digitais UC Digitalis, UC Pombalina e UC Impactum, pressupõem a aceitação plena e sem reservas dos Termos e Condições de Uso destas Bibliotecas Digitais, disponíveis em https://digitalis.uc.pt/pt-pt/termos.

Conforme exposto nos referidos Termos e Condições de Uso, o descarregamento de títulos de acesso restrito requer uma licença válida de autorização devendo o utilizador aceder ao(s) documento(s) a partir de um endereço de IP da instituição detentora da supramencionada licença.

Ao utilizador é apenas permitido o descarregamento para uso pessoal, pelo que o emprego do(s) título(s) descarregado(s) para outro fim, designadamente comercial, carece de autorização do respetivo autor ou editor da obra.

Na medida em que todas as obras da UC Digitalis se encontram protegidas pelo Código do Direito de Autor e Direitos Conexos e demais legislação aplicável, toda a cópia, parcial ou total, deste documento, nos casos em que é legalmente admitida, deverá conter ou fazer-se acompanhar por este aviso.

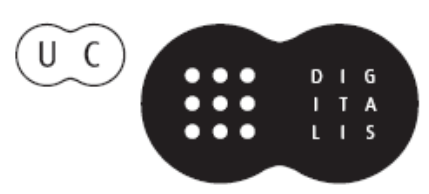


Maria Manuela Tavares Ribeiro

Coordenação

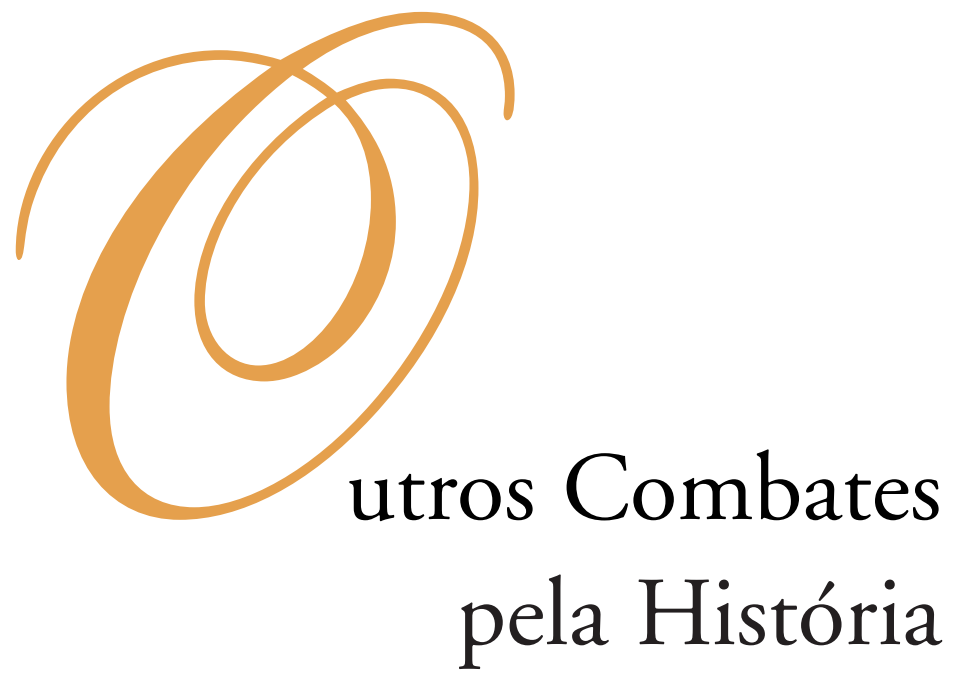




\section{COORDENAÇĀO EDITORIAL}

Imprensa da Universidade de Coimbra

Email: imprensauc@ci.uc.pt

URL: http://www.uc.pt/imprensa_uc

Vendas online: http://livrariadaimprensa.com

\section{CONCEPÇÃO GRÁFICA}

António Barros

\section{ORgANIZAÇĀO DOS TEXTOS}

Isabel Maria Luciano

Marlene Taveira

PRÉ-IMPRESSÃO

António Resende

Imprensa da Universidade de Coimbra

EXECUÇÃO GRÁFICA

SerSilito • Maia

ISBN

978-989-26-0041-3

DEPósito LEGAL

OBRA PUBLICADA COM O APOIO DE:

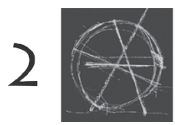

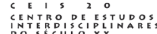

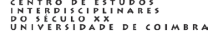

FCT Fundação para a Ciência e a Tecnologia

MINISTÉRIO DA CIÊNCIA, TECNOLOGIA E ENSINO SUPERIOR Portugal

Programa Operacional Ciência, Tecnologia, INOVAÇĀo DO QUADRo COMUNITÁRIO DE APOIO III

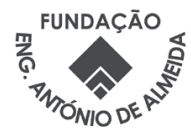

C JULHO 2010, IMPRENSA DA UNIVERSIDADE DE COIMBRA 
Maria Manuela Tavares Ribeiro

Coordenação

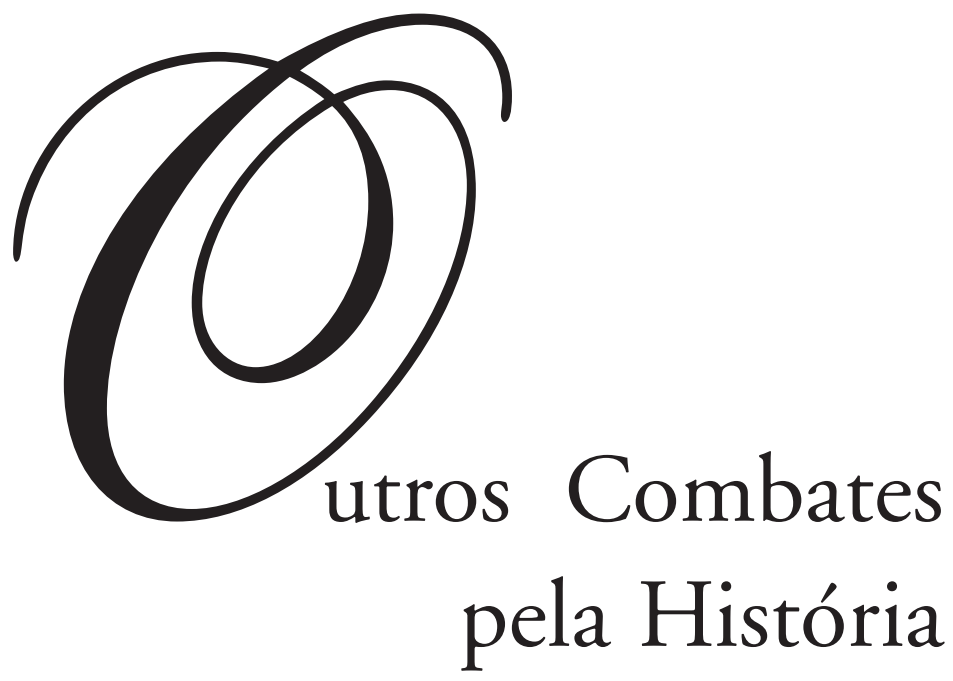

- colmbra 2010 
história, EducaÇÃo e ComunicaÇão 


\section{António Simões Rodrigues}

\section{Para outras leituras da História da EducaÇÃo. O PAPEL DA ARQUITECTURA ESCOLAR}

Começo por me congratular com a caminhada encetada, há dez anos pelo Centro de Investigação Interdisciplinar do Século XX da Universidade de Coimbra ao qual estou ligado desde a primeira hora. Quis também estar presente e acompanhar a merecida homenagem ao Prof. Reis Torgal, um amigo de longa data, um humanista a quem se reconhece um enorme sentido profissional e a grande solidariedade que soube viver e transmitir a todos os que com ele trabalham. As suas inegáveis qualidades de Professor cultivadas na exigência, no rigor, no sentido crítico que amalgamou de forma singular com a tolerância e a afectividade, gerando a autenticidade de uma escola que esteve e está muito para além do que é institucional.

Desejo ao Professor Reis Torgal a continuação do seu meritório trabalho em prol da cultura e do CEIS20 que criou e dinamizou com particular dedicação.

Depois desta breve introdução passo à temática que me propus abordar.

Os estudiosos da História da Educação reconhecem hoje a importância do espaço escolar, espaço de socialização e de instrução, cenário onde os protagonistas da relação pedagógica e da acção educativa se encontram e desempenham os seus papéis. A arquitectura como toda a construção humana espelha um contexto histórico-cultural, traduz aspirações sociais e reflecte o gosto, a idealização da vida, a sensibilidade estética, o génio e as fantasias dos projectistas. No entanto a criatividade esbarra muitas vezes com o poder, com as regras a que deve obedecer o projecto do chamado templo laico, definindo os seus espaços concebidos em função de objectivos específicos, ligados a valores e interesses sociais. O desenho do espaço escolar tornou-se cada vez mais importante à medida que o sujeito educativo passou a ser a criança, que necessita de crescer em ambiente acolhedor e saudável. A localização no tecido urbano, a ambiência paisagística, os custos, as tecnologias, os materiais a utilizar são outros condicionantes nos projectos arquitectónicos.

Dada a extensão da matéria e as limitações do tempo, iremos apenas tratar da arquitectura escolar primária, tentando conjugar a palavra e a imagem já que esta no seu poder descritivo, ajuda-nos a revigorar a memória da escola que tivemos ou que gerações anteriores frequentaram. Trata-se de um espaço mitificador, legendário onde cresceram e se movimentaram crianças, intervieram professores na orientação da 
aprendizagem, estimulando, nem sempre da forma mais acertada, o desenvolvimento cognitivo e sócio-afectivo dos alunos. São espaços onde mergulham as raízes da nossa cultura, testemunhos de outros tempos, de outras mentalidades, de outras visões de ensino que não deixam de marcar o nosso imaginário colectivo, alicerçar a nossa identidade. São espaços a que nos ligam múltiplas recordações, designadamente de colegas com quem partilhamos sonhos, com quem aprendemos a observar com um outro olhar a realidade, rasgando horizontes que já não se confinavam ao meio familiar. Recordaçôes marcadas pela afectividade, pelo desejo de aprender, de decifrar o mistério das letras e dos números. Recordações do espírito de companheirismo, das brincadeiras, dos jogos, dos passeios, do convívio, da amizade nascida na primeira caminhada das nossas vidas. Mas também recordaçôes menos agradáveis, resultantes do confronto entre a ânsia da liberdade de uma criança e as exigências do quotidiano escolar e o sentimento de justiça ferida pela aplicação de certos castigos. E a propósito destes vem-me à memória a afirmação produzida em 1931, no X Congresso de Protecção à Infância em que o Ministro da Justiça, José de Almeida Eusébio afirmava: «Educar é sempre torcer, podar, cortar, contrariar e esmagar». Infelizmente este espírito reinou durante tempos infindos em muitas escolas. A repressão educativa era uma realidade com contornos diversos e de difícil esvaziamento. Mas, voltemos à história, deixemos para trás séculos de escola quando esta estava ligada à igreja secular, à monástica, aos municípios, aos particulares, ou quando mais tarde, no tempo da reforma pombalina as escolas régias assumiram o primeiro patamar do nosso ensino público, numa afirmação do Estado como responsável pela educação.

Vamos então na nossa rápida incursão pela história da educação a partir da revolução liberal que perspectivou a educação como uma necessidade dos povos, o caminho para o progresso, a tarefa central da vida social, bem na linha dos ideais iluministas. Estamos no século XIX que alimentou o mito da educação, fomentando reflexões teóricas e práticas. Foi também a época em que o movimento romântico envolveu todos os campos da criação artística, todo o mundo da cultura, produzindo mudanças na mentalidade europeia. Mas se o mundo da cultura e da ciência projectava uma outra visão da criança, o dinamismo da revolução industrial, os progressos da técnica e da ciência fizeram emergir uma nova consciência educativa. As exposiçôes universais que se iam realizando nalgumas cidades europeias também deram alento às mudanças na aprendizagem ao apresentar projectos mais racionalizados e atractivos de edifícios escolares, ao dar a conhecer novos equipamentos, particularmente modelos de carteiras, ao proporcionar material didáctico mais sugestivo e motivador.

Se se pretendia uma escola, de todos e para todos, formando o homem e o cidadão, tornada centro de gravidade da vida social, não podíamos manter um parque escolar sem qualidade, sem condições higiénicas, sem o mínimo conforto.

Não era possível cumprir o preceito da Constituição de 1822 que determinava que em todos os lugares do reino funcionassem escolas de primeiras letras, numa altura em que havia uma escola por $120 \mathrm{~km}^{2}$.

As nossas escolas de primeiras letras funcionavam em velhos edifícios conventuais, em casas municipais ou particulares conhecidas por casa da escola, onde as salas de aula eram por vezes, mal iluminadas e arejadas, onde o frio ou o calor se fazia sentir, e mal apetrechadas de mobiliário escolar, tornando pouco motivadora e aliciante a vida dos pequenos estudantes. Se às deficientes condiçôes em que se desenrolavam os 
trabalhos escolares juntarmos um ensino marcado por tarefas mecânicas, rotineiras, mnemónicas e onde os castigos corporais eram frequentes, temos de reconhecer que não era fácil a vida das crianças a quem não era permitido sonhar, soltar a imaginação, desenvolver a criatividade, dialogar, encontrar respostas ao seus porquês, fortalecer a afectividade. A nossa literatura dá-nos algumas imagens da escola, como por exemplo, Feliciano de Castilho, defensor de um sistema de alfabetização e de escolarização, e teorizador do método de Leitura Repentina, escrevia, em 1863, numa dedicatória ao rei D. Luís, na sua obra «O Outono»:

«Entre-se numa escola velha. Sente-se logo o que seja repugnância, de terror, de reprovação instintiva, de excreção involuntária, vendo naquele espaço estreito, mal arejado, nem sempre bem iluminado, desgracioso, fétido, um bando de inocentes condenados à imobilidade, ao silêncio, ao pasmo estúpido, sobre bancos duros e sem encosto, como os das galés, com pernas pendentes, os olhos automaticamente fitos sobre o indecifrável e odioso enigma de uma página, isto em face de um mestre antipático, tão cativo, tão desgraçado como eles, seu tiranizado e seu tirano, alternativamente, e a cujo lado avultam brasões milenários do ensino desnatural, os instrumentos de dor e de vergonha, os impotentes auxiliares de impotência dele: a vara, a férula, as orelhas asininas».

Bem tentaram governantes como Rodrigo da Fonseca pela lei de 7 de Setembro de 1835, ou Costa Cabral pela lei de 20 de Setembro de 1844 alterar a situação e determinar que as escolas primárias deveriam funcionar em edifícios públicos especialmente preparados para esse fim. Reconhecia-se que a "casa da escola» tinha condições em muitos casos, degradantes, como deixa parecer uma nota do governo regenerador, enviada em 1863, aos inspectores escolares. Mas para além da falta de qualidade dos edifícios escolares, o seu número era exíguo, não respondia ás necessidades de um ensino que se pretendia alargar a números cada vez maior de crianças. Em 1862 havia em Portugal 1553 escolas públicas e 1117 livres. O distrito de Aveiro tinha 96 escolas públicas e 55 livres.

As primeiras normas portuguesas para regulamentar a construção dos edifícios escolares foram publicadas em 1866. Inspiravam-se na legislação francesa de 1858 e tentaram acompanhar o que se fazia para além-Pirinéus. Passava a haver regras sobre a localização, os edifícios deveriam ser construídos em locais nobres dos centros urbanos, afastadas de zonas perigosas para a saúde física e moral das crianças. A área das salas de aula seria proporcional ao número de crianças, cerca de $1 \mathrm{~m}^{2}$ por aluno. Iluminada e arejada por amplas janelas de $1,20 \mathrm{~m}$ de largura colocadas a uma altura que não permitia a quem estava sentado nas carteiras visionar o que se passava fora, facilitando assim a concentração, fundamental na aprendizagem. As escolas deveriam ter também uma sala destinada às festas escolares e uma biblioteca. A entrada principal era encimada por um campanário que recordava aos alunos a obrigação da aula e estimulava o professor à pontualidade. No teto da sala de aula poderia ser pintada uma rosa-dos-ventos com um anemoscópio que ajudaria a conhecer as observações meteorológicas.

A legislação de 1866 permitiu regulamentar as escolas construídas, graças ao testamento do Conde Ferreira, um emigrante bem sucedido em terras brasileiras e que ao regressar a Portugal dedicou-se à vida empresarial e política, tornando-se um benemérito, auxiliando as misericórdias do Porto e do Rio de Janeiro, apoiando a 
construção de hospitais e legando por testamento a importância de 144.000 reis para ajudar a construção de 120 escolas primárias. O projecto era único, os municípios deveriam colaborar cedendo os terrenos em local apropriado e saudável. O governo atribuía um subsídio de 10.000 reis ajudando a financiar as obras, mas impondo o rigoroso cumprimento do programa.

Em 1875 um inquérito mandado realizar pelo governo de Fontes Pereira de Melo, revelou que mais de metade das escolas primárias funcionavam em edifícios particulares. D. António da Costa, político e pedagogo, 1884, na obra «Auroras da instrução pela iniciativa particular» dava a conhecer o filantropismo de muitos cidadãos que mandaram construir escolas, ajudando a atenuar as carências do nosso parque escolar.

Os nossos escritores continuavam a tecer duras críticas ao estado das nossas escolas por exemplo, Eça de Queirós na obra «Uma Campanha Alegre» extraída da parte por si elaborada de «As Farpas» escrevia que «os edifícios escolares na sua maior parte são uma variante torpe entre o celeiro e o curral». $\mathrm{O}$ jornal «O Conimbricense» de Janeiro de 1874 referia as condiçóes de funcionamento de uma escola da Tocha, em que a sala de aula não defendia os alunos da chuva, do frio, do calor e que ficava situada por cima do curral do porco. Em 1883 as conferências pedagógicas realizadas em Lisboa também denunciavam a falta de qualidade das nossas escolas e a dificuldade dos professores em tentar, neste cenário, utilizar metodologias menos rígidas e mais motivadoras. A Real Associação dos Arquitectos Civis e Arqueólogos Portugueses, em 1881, fez um estudo sobre o parque escolar e apontou um conjunto de regras a que deviam obedecer as construções dos edifícios.

Em 1897 a Associação dos Engenheiros Portugueses partindo de estudos elaborados anteriormente e de outros realizados na Europa, apresentou um importante trabalho que serviu de base às medidas tomadas pelo governo progressista de Luciano e Castro, que aproveitando um momento de algum alívio das finanças públicas, abriu um concurso destinado à construção de escolas primárias que obedecessem às exigências dos higienistas e dos pedagogos.

O país era dividido em sete regiōes: Minho e Douro, Trás-os-Montes, Beiras, Estremadura, Alentejo, Algarve e Ilhas adjacentes. Cada região deveria utilizar os materiais característicos (granito, xisto, calcário, tijolo, basalto) e usar preferencialmente as técnicas tradicionais. A escola era uma construção que deveria enquadrar-se nas características da região como um elemento integrador da sua identidade.

$\mathrm{O}$ arquitecto Adães Bermudes que cursou na Academia Portuense de Belas Artes do Porto e na Escola de Belas Artes de Paris, apresentou um projecto escolar que viria a ganhar a medalha de ouro da Exposição Internacional de Paris de 1900. Em Março de 1898 Bermudes venceria o concurso aberto pelo governo, para construção de escolas primárias. Apresentou dois projectos para escolas com dimensões diferentes. Em qualquer deles estava contemplada a casa do professor com dois pisos, situada na ala principal. Pretendia-se simbolizar a promoção social do professor como mensageiro da ilustração. Os edifícios escolares inspirados em modelos franceses caracterizavam-se pelo equilíbrio das linhas, pela simetria e simplicidade das fachadas, pela elegância da torre sineira, pelas amplas janelas. As portas e os vãos das janelas apresentavam um friso em tijoleira que no seu colorido dá uma sensação acolhedora, atraente. As salas de aula, revestidas a azulejos na parte interior das paredes, com um pé direito acima 
de 4 metros, dispunham de uma área por aluno superior a um metro quadrado, respondendo às exigências legais. Tinham recreio coberto e ao ar livre, reconhecia-se que estes espaços eram fundamentais na vida escolar. São os locais de encontro, dos jogos, com as suas regras que estimulam a solidariedade de grupo, o fortalecimento da amizade e a disciplina.

Apesar do esforço que ia sendo feito o Regulamento do Ensino Primário de 1902, elaborado no governo de Hintze Ribeiro, reconhecia que as grandes deficiências do parque escolar primário ainda se mantinham. Em 1909, nas vésperas da implementação da República, o inspector Carneiro de Moura afirmava que mais de três mil escolas primárias continuavam a funcionar em edifícios particulares sem as condições exigidas pela lei.

A República com a lei de 29 de Março de 1911 lançava uma profunda reforma do ensino das primeiras letras que tinha como grande objectivo habilitar o homem para a luta da vida. $\mathrm{O}$ ensino primário passava a ser estruturado em três graus: o Elementar de três anos, o Complementar de dois e o Superior.

O parque escolar com o aumento do número de anos de ensino primário no seu conjunto e com o crescimento da população escolar ainda ficou mais limitado e incapaz de responder ás necessidades. Em 1910 o ensino primário era frequentado por 271.830 alunos, subindo, no ano seguinte para 291.800. Em 1911 a República criou mais de 206 escolas do ensino primário, número que continuava a ser exíguo. Em 1913 o governo de Afonso Costa nomeava uma comissão presidida pelo arquitecto Adães Bermudes e de que fazia parte um médico e um professor para elaborar um manual de normas técnicas, pedagógicas e higiénicas, que passaria a regulamentar todas as futuras construções escolares. A verdade é que os edifícios desta época embora em número insuficiente, primaram pela qualidade. As dificuldades que enfrentavam as finanças públicas, sobretudo a partir da $1^{\text {a }}$ Guerra Mundial, tornaram limitadora a acção dos governos no investimento no campo de ensino. A criação das escolas móveis nas freguesias onde não havia possibilidade de funcionar escolas fixas ajudou a partir de 1913 a atenuar o problema. Estas escolas seriam extintas em 1930 pela Ditadura militar. A filantropia de cidadãos ou nalguns casos a acção das populações contribuíram para que novos edifícios escolares fossem construídos. Apesar das vozes críticas que se faziam ouvir um pouco por todo o lado, a situação não era fácil de resolver, o Estado e as câmaras municipais não conseguiam orçamentar as verbas necessárias e os empreiteiros queixavam-se do aumento contínuo do custo das obras e da falta de materiais o que tornava difícil o seu acabamento. O jornal «O Professor Primário» de 2 de Novembro de 1924 escrevia "O vergonhoso vexame porque está passando a escola popular com os despejos constantes a intermináveis (por falta de pagamento das rendas), suprema falência da nossa instrução nacional».

Muitos projectos escolares de inegável qualidade foram aprovados, mas por falta de verbas não foram concluídos ou nalguns casos as obras nem sequer foram iniciadas. Os edifícios escolares projectados na República e que foram construídos entre 1926-1935 são designados por Projectos Antigos ou Projectos-tipo. Todos foram codificados segundo as sete regiōes estabelecidas em 1897 pela Associação dos Engenheiros Portugueses, anteriormente referida. Foram projectos assinados por arquitectos de grande prestígio como Jorge Segurado, Jorge Bermudes, Frederico de Carvalho, Guilherme Rebelo de Andrade, Eugénio Correia. Vejamos algumas imagens reveladoras 
da beleza e da qualidade destes edifícios escolares como o de Ançã (Cantanhede), Valença (Minho), Azenhas do Mar (Sintra).

São projectos de dois pisos, de grande funcionalidade caracterizada pelo geometrismo das suas linhas arquitectónicas. Para além das salas de aula amplas, tinham um museu-biblioteca, gabinete para professores e recreio coberto.

A política seguida pela Ditadura Militar e pelos primeiros anos do Estado Novo não beneficiaram as construções escolares. A redução dos anos de ensino primário para três e o fechar de escolas primárias por Cordeiro Ramos, desde que tivessem uma frequência de menos de quarenta alunos, revela o pouco interesse pelo ensino das primeiras letras. Tentava-se atribuir aos municípios a responsabilidade da construção e manutenção das escolas primárias, o Estado apenas subsidiava. Entretanto os edifícios concluídos após o 28 de Maio de 1926 deveriam ter uma placa com a inscrição "concluído pelo governo da Ditadura em 19...».

Uma vez mais será a acção dos beneméritos a ajudar a suprimir as deficiências do nosso parque escolar primário, até porque o Salazarismo virava as suas atenções para edifícios a construir dos ensinos liceal, técnico e universitário.

O Ministro das Obras Públicas, Eng. Duarte Pacheco reunia á sua volta nomes consagrados da engenharia e arquitectura portuguesa e fazia aprovar, em 1935, os Projectos de Tipo Regionalizado dos arquitectos Rogério de Azevedo e Raul Lino. Alguns belos edifícios, como se pode observar pelas imagens, apresentam um bom enquadramento paisagístico e urbano apostando na funcionalidade.

Salazar havia limitado, na década de trinta, as verbas para a construção de escolas primárias, alegando dificuldades das Finanças Públicas. Mas no ano de 1940, o Estado Novo em período de grande afirmação, de exaltação patriótica e de apoteose do regime lançava-se nas comemorações do $8^{\circ}$ Centenário da fundação de Portugal e no $3^{\circ}$ Centenário da Restauração. Pretendia-se dar ao mundo a imagem de um regime que proporcionava a paz e o progresso, numa altura em que a Europa se destruía nos

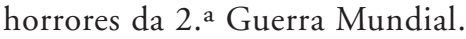

Em 15 de Julho de 1941, um despacho de Salazar definia o Plano da Rede de Escolas do Ensino Primário e dos Postos Escolares. Reconhecia-se a falta de qualidade da grande parte dos edifícios escolares primários e propunha-se que de futuro as escolas a construir pelas câmaras fossem apoiadas pelo Estado. Da escola modelo de uma sala de aula para quarenta alunos, partia-se para outras de maiores dimensões a erguer nos centros urbanos mais populosos. $\mathrm{O}$ texto defendia a utilização de materiais de construção característicos de cada região e nele escrevia-se: «Se a casa portuguesa oferece, pelos materiais ou linha exterior, a marca regional que faz diferir do Alentejo para a Beira ou para Trás-os-Montes, não havia desculpa para a implantação por toda a parte de um tipo abstracto, número banal de série. E concluía-se: «é preciso confiarmos nos arquitectos de gosto a solução do problema». As escolas primárias a construir iam melhorar substancialmente as condições do ensino.

O projecto do Plano dos Centenários foi concebido pelo arquitecto Manuel Fernandes de Sá que se apoiou nos trabalhos produzidos anteriormente pelos seus colegas Rogério de Azevedo e Raul Lino, que acabariam por ser um tanto marginalizados pelo regime. Com o decorrer do tempo e a partir de 1946, numa tentativa de reduzir o custo das obras, estas foram perdendo qualidade. Em 1959 o governo reconhecia que ainda estavam por construir 3.228 escolas, a explosão escolar do início da 
década mostrava a incapacidade do Regime em resolver satisfatoriamente o problema. Entre 1926 a 1960 a população escolar primária duplicou. As escolas do Plano dos Centenários erguidas por todo o país, não deixaram de representar uma importante mensagem de propaganda do regime, que até afirmava ter sido o único capaz de dar solução às carências do parque escolar primário.

Em 1961, os Ministros das Obras Públicas e da Educação, Eng. ${ }^{\circ s}$ Arantes e Oliveira e Leite Pinto tentaram melhorar a situação do nosso ensino dinamizando um novo Plano de Construçôes Escolares que também respondesse ao encontro das orientações saídas do Projecto Regional do Mediterrâneo. Algumas escolas construídas como a de Mem Martins, em Lisboa, foram financiadas pela OCDE e marcaram uma ruptura com as concepções arquitectónicas anteriores. São projectos como o da Fonte da Moura, no Porto, conhecida pela "escola de vidro" que não se restringem à sala de aula. A sua concepção, o desenho das suas amplas divisões, facilita a utilização de práticas pedagógicas diversificas e a possibilidade de uma maior abertura à comunidade. 
Série

Documentos

Imprensa da Universidade de Coimbra

Coimbra University Press

2010

- U

C • 